Document downloaded from:

http://hdl.handle.net/10251/48246

This paper must be cited as:

Peidro Payá, D.; Mula, J.; Alemany Díaz, MDM.; Lario Esteban, FC. (2012). Fuzzy multiobjective optimisation for master planning in a ceramic supply chain. International Journal of Production Research. 50(11):3011-3020. doi:10.1080/00207543.2011.588267

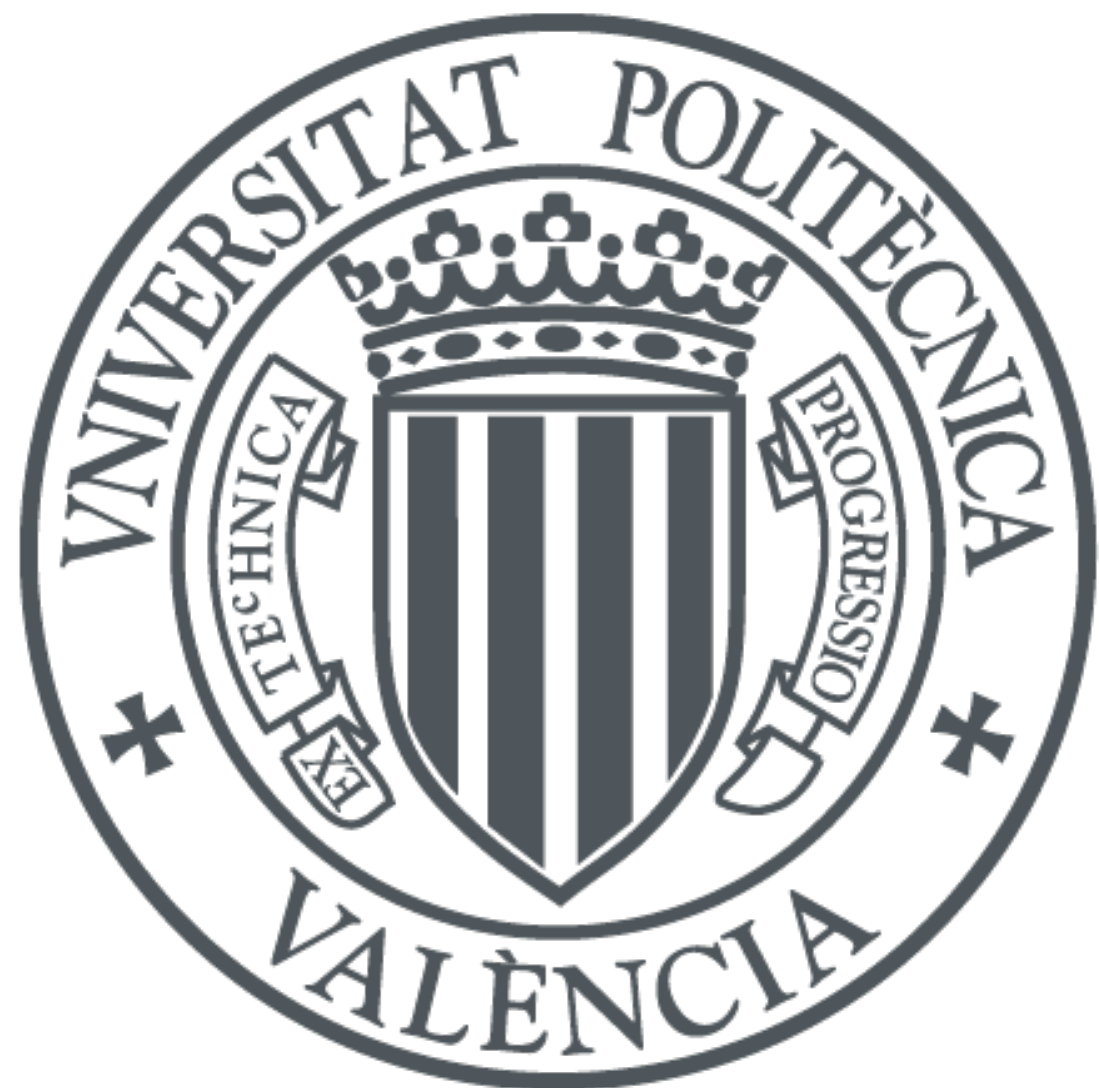

The final publication is available at

http://www.tandfonline.com/10.1080/00207543.2011.588267

Copyright Taylor \& Francis

Additional Information

This is an Accepted Manuscript of an article published in International Journal of Production Research on 2012, available online:

http://www.tandfonline.com/10.1080/00207543.2011.588267. 


\title{
Fuzzy multi-objective optimisation for master planning in a ceramic supply chain ${ }^{* *}$
}

\author{
David Peidro*, Josefa Mula, M.M.E. Alemany, Francisco-Cruz Lario \\ Centro de Investigación de Gestión e Ingeniería de Producción (CIGIP) \\ Universidad Politécnica de Valencia, Spain
}

\begin{abstract}
In this paper, we consider the master planning problem for a centralised replenishment, production and distribution ceramic tile supply chain. A fuzzy multi-objective linear programming (FMOLP) approach is presented which considers the maximisation of the fuzzy gross margin, the minimisation of the fuzzy idle time and the minimisation of the fuzzy backorder quantities. By using an interactive solution methodology to convert this FMOLP model into an auxiliary crisp singleobjective linear model, a preferred compromise solution is obtained. For illustration purposes, an example based on modifications of real-world industrial problems is used.
\end{abstract}

Keywords: Master planning, supply chain, ceramic sector, fuzzy multi-objective model.

\section{Introduction}

A supply chain (SC) may be considered an integrated process in which a series of several organisations (e.g., suppliers, manufacturers, distributors, shops), work together to acquire raw materials and to convert these materials into finished goods to be distributed to shops (Beamon, 1998). Integrated SC management optimises the SC as a whole by simultaneously considering planning for all the links involved. Thus to obtain optimum solutions to minimise costs, several authors have studied SC production planning with mathematical programming models (for instance, von Lanzenauer and Pil-Glombik (2002); Kreipl and Pinedo (2004); Chen and Lee (2004); Park (2005); Peidro et al. (2009b); Mula et al. (2010b)). For an extensive review, we refer readers to Peidro et al. (2009a) and Mula et al. (2010a).

Recently, Alemany et al. (2010) proposed a centralised mixed integer linear programming model for the master planning problem for the replenishment-production-distribution of SCs in the ceramic sector for the purpose of maximising the total gross margin in multi-supplier, multi-plant, multi-type, multi-level distribution centres with a multi-item and multi-period logistic environment. The contemplated model was inspired by an actual case and includes the most relevant characteristics of the ceramic sector. It also considers the several distribution levels integrated by nodes of various types.

\footnotetext{
** This research has been carried out in the framework of a project funded by the Science and Technology Ministry of the Spanish Government, entitled "Project of reinforcement of the competitiveness of the Spanish managerial fabric through the logistics as a strategic factor in a global environment". Ref. PSE-370000-20088.

${ }^{*}$ Corresponding author. David Peidro, Dpto. Organización de Empresas, Universidad Politécnica de Valencia, Plaza Ferrándiz y Carbonell, 2, 03801, Alcoy, SPAIN. Tel.: + 349665284 90. Fax: +34 9665285 85. Email addresses: dapeipa@cigip.upv.es, fmula@cigip.upv.es, mareva@omp.upv.es, fclario@cigip.upv.es
} 
Continuing the work of Alemany et al. (2010), this paper proposes a fuzzy multi-objective linear programming model (FMOLP) for the master planning problem for replenishment, production, and distribution in a ceramic tile SC. The objectives in conflict to simultaneously optimise are to: (i) maximise the fuzzy gross margin (incomes minus costs), (ii) minimise the fuzzy idle time of the production resources, and (iii) minimise the fuzzy backorder quantities. The aspiration levels of these three objectives can be considered fuzzy in nature because of the incompleteness and/or unavailability of the data required over the planning horizon, which could be obtained by being subjectively based on the planner's experience. Then, an interactive solution methodology to solve the FMOLP problem for the purpose of finding a preferred compromise solution is applied, which is based on the work of Torabi and Hassini (2008). For other solution methodologies to solve fuzzy multi-objective approaches, readers are referred to Zimmerman (1978), Lai and Hwang (1993), Li et al. (2006) and Selim and Ozkarahan (2008).

In relation to the previous work by Alemany et al. (2010), this fuzzy model is able to obtain better performance in terms of minimising the idle time of the production resources without lowering gross margin levels or increasing backorder levels, which is desirable for the entire SC. Other multiobjective applications for SC planning may be found in Chen and Lee (2004), Chern and Hsieh (2007) and Selim et al. (2008).

The rest of this article is arranged as follows. Section 2 formulates a FMOLP model for the master planning problem in a ceramic tile SC. Section 3 describes its solution methodology. Section 4 validates and evaluates the proposed model by using an example based on a real-world problem. Section 5 offers conclusions and further research.

\section{Fuzzy multi-objective linear programming for ceramic supply chain planning}

\subsection{Assumptions and nomenclature}

This section formulates the FMOLP model for master planning in a ceramic tile SC. This model considers the following assumptions which are justified in detail in Alemany et al. (2010):

- The flow of parts, components, raw materials (RMs) and finished goods (FGs) that might circulate between the nodes is known beforehand.

- There are several production plants supplied with various RMs provided by different suppliers with a limited supply capacity.

- Each production plant has one or several parallel production lines, which process different FGs with a limited capacity.

- There are FGs that are manufactured only in production plants; others may be partly subcontracted, while some may be totally subcontracted to external suppliers.

- For commercial reasons and for saving setups, FGs are grouped into product families, which are assigned to the production lines.

- The minimum run lengths for product families are specified.

- The item setups also exist among the products belonging to the same product family.

- Minimum lot sizes for those products manufactured on a specific line are considered.

- The distribution of FGs from production plants to end customers is carried out in various stages by different types of distribution centres, such as central warehouses, logistic centres and shops.

- Neither manufactured nor subcontracted FGs can be stored in manufacturing plants. They are sent to the central warehouses, which have a limited storage capacity.

- The outgoing FGs from the central warehouses cover the demand of both end customers and supply logistics centres.

- Logistics centres supply FGs to the shops previously assigned to them.

- Shops attend to end customers' demands. 
- Limited backorders are permitted in both central warehouses and shops.

The nomenclature defines the indices, sets of indices, parameters and decision variables (Table 1).

Table 1. Nomenclature.

\begin{tabular}{|c|c|c|c|}
\hline \multicolumn{4}{|l|}{ Indices } \\
\hline$c$ & RMs, items, and components $(c=1 \ldots C)$ & $q$ & Logistic centres $(\mathrm{q}=1 \ldots Q)$ \\
\hline$i$ & FGs $(i=1 \ldots I)$ & $w$ & Shops $(w=1 \ldots W)$ \\
\hline$f$ & Product families $(\mathrm{f}=1 \ldots F)$ & $r$ & \multirow{2}{*}{$\begin{array}{l}\text { Suppliers of RMs, items, and components } \\
(\mathrm{r}=1 \ldots R)\end{array}$} \\
\hline$l$ & Production lines $(l=1 \ldots L)$ & & \\
\hline$p$ & Production plants $(\mathrm{p}=1 \ldots P)$ & $b$ & Suppliers of FGs $(b=1 \ldots B)$ \\
\hline$a$ & Warehouses $(a=1 \ldots A)$ & $t$ & Time periods $(t=1 \ldots T)$ \\
\hline \multicolumn{4}{|c|}{ Sets of Indices } \\
\hline $\operatorname{Il}(l)$ & $\begin{array}{l}\text { Set of FGs that can be manufactured on } \\
\text { manufacturing line } l\end{array}$ & $L p(p)$ & $\begin{array}{l}\text { Set of manufacturing lines that belong to } \\
\text { production plant } p\end{array}$ \\
\hline$F l(l)$ & $\begin{array}{l}\text { Set of product families that can be manufactured } \\
\text { on manufacturing line } l\end{array}$ & $P a(a)$ & $\begin{array}{l}\text { Set of production plants that can send FGs to } \\
\text { warehouse } a\end{array}$ \\
\hline$I f(f)$ & Set of FGs that belong to product family $f$ & $A q(q)$ & $\begin{array}{l}\text { Set of warehouses that can supply logistics centre } \\
q\end{array}$ \\
\hline $\operatorname{Ip}(p)$ & $\begin{array}{l}\text { Set of FGs that can be produced in production } \\
\text { plant } p\end{array}$ & $R c(c)$ & Set of suppliers that can supply RM $c$ \\
\hline $\operatorname{Ia}(a)$ & Set of FGs that can be stored in warehouse $a$ & $R p(p)$ & $\begin{array}{l}\text { Set of suppliers of RMs that can supply } \\
\text { production plant } p\end{array}$ \\
\hline$I c(c)$ & & $\operatorname{Cr}(r)$ & \\
\hline PFNS & Set of FGs that cannot be subcontracted & $Q a(a) \quad \mathrm{S}$ & \\
\hline PFSP & $\begin{array}{l}\text { Set of FGs that can be subcontracted either } \\
\text { partially or completely }\end{array}$ & $W q(q) \quad \mathrm{S}$ & $\begin{array}{l}\text { Set of logistics centres that can be supplied by } \\
\text { warehouse } a \\
\text { Set of shops that can be supplied by logistics } \\
\text { centres } q\end{array}$ \\
\hline PFST & $\begin{array}{l}\text { Set of FGs that are compulsorily subcontracted } \\
\text { completely }\end{array}$ & $Q w(w)$ & $\begin{array}{l}\text { Set of logistics centres capable of supplying shop } \\
w\end{array}$ \\
\hline $\operatorname{Iq}(q)$ & Set of FGs that can be sent to logistics centre $q$ & $B i(i)$ & $\begin{array}{l}\text { Set of suppliers of FGs } i \text { to which the FG may be } \\
\text { subcontracted }\end{array}$ \\
\hline $\operatorname{Iw}(w)$ & Set of FGs that can be sent to shop $w$ & $B a(a)$ & $\begin{array}{l}\text { Set of suppliers of FGs that can supply warehouse } \\
a\end{array}$ \\
\hline$L f(f)$ & $\begin{array}{l}\text { Set of manufacturing lines that may produce } \\
\text { product family } f\end{array}$ & $A b(b)$ & $\begin{array}{l}\text { Set of warehouses that can be supplied by the } \\
\text { supplier } b \text { of FGs }\end{array}$ \\
\hline Model & rs & & \\
\hline$c a_{c r t}$ & $\begin{array}{l}\text { Capacity (units) of supplying RM } c \text { of } \\
\text { supplier } r \text { in period } t\end{array}$ & $M 1, M 2$ & Very 1 \\
\hline $\operatorname{costtp}_{c r p}$ & $\begin{array}{l}\text { Cost of purchase and transport of one unit } \\
\text { of RM } c \text { from supplier } r \text { to production plant } \\
p\end{array}$ & capal $_{a}$ & Storage capacity $\left(\mathrm{m}^{2}\right)$ in warehouse $a$ \\
\hline$c a f_{l p t}$ & $\begin{array}{l}\text { Production capacity available (time) of } \\
\text { production line } l \text { at plant } p \text { during time } \\
\text { period } t\end{array}$ & costtcliaq $_{i}$ & $\begin{array}{l}\text { Cost of transporting one } \mathrm{m}^{2} \text { of FG } i \text { from } \\
\text { warehouse } a \text { to logistics centre } q\end{array}$ \\
\hline $\mathrm{cm}_{i}$ & $\begin{array}{l}\text { Loss ratio of FG } i \text {. It represents the } \\
\text { percentage of faulty } \mathrm{m}^{2} \text { obtained due to the } \\
\text { intrinsic characteristics of the production } \\
\text { process in the ceramics sector. }\end{array}$ & costina $_{i a}$ & $\begin{array}{l}\text { Cost of making an inventory of one } \mathrm{m}^{2} \text { of } \\
\text { FG } i \text { in the warehouse over a time period }\end{array}$ \\
\hline$c q_{i}$ & $\begin{array}{l}\text { First quality coefficient of FG } i \text {. It } \\
\text { represents the percentage of } \mathrm{m}^{2} \text { that can be } \\
\text { sold as first quality. }\end{array}$ & costdifa $a_{i a}$ & $\begin{array}{l}\text { Cost of backordering one } \mathrm{m}^{2} \text { of demand of } \\
\text { FG } i \text { in warehouse } a \text { over a time period }\end{array}$ \\
\hline $\operatorname{costta}_{i p a}$ & $\begin{array}{l}\text { Cost of transporting one } \mathrm{m}^{2} \text { of } \mathrm{FG} i \text { from } \\
\text { production plant } p \text { to warehouse } a\end{array}$ & $p a_{i a}$ & $\begin{array}{l}\text { Sales value of one } \mathrm{m}^{2} \text { of FG } i \text { in warehouse } \\
a\end{array}$ \\
\hline $\operatorname{costp}_{i l p}$ & $\begin{array}{l}\text { Cost of producing one } \mathrm{m}^{2} \text { of } \mathrm{FG} i \text { on } \\
\text { production line } l \text { of production plant } p\end{array}$ & $d a_{\text {iat }}$ & $\begin{array}{l}\text { External demand }\left(\mathrm{m}^{2}\right) \text { of } \mathrm{FG} i \text { at the } \\
\text { warehouse } a \text { in period } t\end{array}$ \\
\hline costsetu & $\begin{array}{l}\text { Setup costs for product family } f \text { on } \\
\text { production line } l \text { of production plant } p\end{array}$ & $s s a_{i a}$ & Safety stock $\left(\mathrm{m}^{\frac{1}{2}}\right)$ of FG $i$ at warehouse $a$ \\
\hline
\end{tabular}


Maximum backorder quantity permitted over a time period in warehouses expressed as a percentage of the demand of that time period

Cost of subcontracting one $\mathrm{m}^{2}$ of FG $i$ to FG supplier $b$

Minimum amount $\left(\mathrm{m}^{2}\right)$ of $\mathrm{FG} i$ to be subcontracted to FG supplier $b$

Cost to transport one $\mathrm{m}^{2}$ of $\mathrm{FG} i$ from logistics centre $q$ to shop $w$

Cost to backorder one $\mathrm{m}^{2}$ of the demand of FG $i$ over a time period at shop $w$

Sales price of one $\mathrm{m}^{2}$ of FG $i$ in shop $w$

External demand $\left(\mathrm{m}^{2}\right)$ of FG $i$ in shop $w$ over the time period $t$

Maximum backorder quantity permitted in a period in shops expressed as a percentage of the demand of that period

casc $_{i b t} \quad$ Supply capacity $\left(\mathrm{m}^{2}\right)$ of FG $i$ of supplier $b$ over time period $t$

\section{Decision Variables}

CTP crpt Amount of RM $c$ to be purchased and transported from supplier $r$ to production plant $p$ over time period $t$

$I N C_{c p t}$ Inventory of the RM $c$ at plant $p$ at the end of time period $t$

$M P F_{f l p t} \quad$ Amount $\left(\mathrm{m}^{2}\right)$ of product family $f$ manufactured on production line $l$ of production plant $p$ over time period $t$

$M P_{i l p t}$ Amount $\left(\mathrm{m}^{2}\right)$ of $\mathrm{FG} i$ manufactured on production line $l$ of production plant $p$ over time period $t$

$X_{i l p t} \quad$ Binary variable with a value of 1 if FG $i$ is manufactured on production line $l$ of production plant $p$ over time period $t$, and with a value of 0 otherwise

$Y_{f l p t} \quad$ Binary variable with a value of 1 if product family $f$ is manufactured on production line $l$ of production plant $p$ over time period $t$, and with a value 0 otherwise

$Z I_{i l p t} \quad$ Binary variable with a value of 1 if a setup takes place of product $i$ on production line $l$ of production plant $p$ over time period $t$, and with a value of 0 otherwise

$Z F_{f l p t} \quad$ Binary variable with a value of 1 if a setup takes place of product family $f$ on production line $l$ of production plant $p$ over time period $t$, and with a value of 0 otherwise

$C T A_{\text {ipat }}$ Amount $\left(\mathrm{m}^{2}\right)$ of $\mathrm{FG} i$ to be transported from production plant $p$ to warehouse $a$ over time period $t$

$I N A_{\text {iat }}$ Inventory $\left(\mathrm{m}^{2}\right)$ of FG $i$ in warehouse $a$ over time period $t$

$C S C_{i b a t}$

$S_{i b t}$

$V E A_{\text {iat }}$

$D I F A_{\text {iat }}$

$C T C L_{\text {iaqt }}$

Amount $\left(\mathrm{m}^{2}\right)$ of $\mathrm{FG} i$ transported from warehouse $a$ to logistics centre $q$ over time period $t$

CTTK $K_{\text {iqwt }}$ Amount $\left(\mathrm{m}^{2}\right)$ of $\mathrm{FG} i$ transported from logistics centre $q$ to shop $w$ over time period $t$

$V_{E T K_{i w t}}$ Amount $\left(\mathrm{m}^{2}\right)$ of FG $i$ sold in shop $w$ over time period $t$

DIFTK $_{i w t}$ Backorder quantity $\left(\mathrm{m}^{2}\right)$ of FG $i$ in shop $w$ over time period $t$

The formulation of the model is as follows. 


\subsection{Objective functions}

There are three objectives in conflict to simultaneously optimise.

\section{Objective $1\left(z_{1}\right)$}

To maximise the total gross margin over the time periods computed by subtracting costs from the revenues produced by sales in central warehouses and shops. Total costs include transport and purchase costs of RMs; production costs of FGs; setup costs of product families and FGs in the production plants; transport costs of FGs; storage costs; and subcontracting costs of FGs.

$$
\begin{aligned}
& \operatorname{Max} z_{1} \cong \sum_{t} \sum_{i}\left(\sum_{a} p a_{i a} * V E A_{i a t}+\sum_{w} p w_{i w} * V E T K_{i w t}\right) \\
& -\sum_{t} \sum_{p} \sum_{r \in R p(p)} \sum_{c \in C r(r)} \cos t t p_{c r p} * C T P_{c r p t}-\sum_{t} \sum_{p} \sum_{l \in L p(p)} \sum_{i \in I l(l)} \cos t p_{i l p} * M P_{i l p t} \\
& -\sum_{t} \sum_{p} \sum_{l \in L p(p)} \sum_{f \in F l(l)} \cos \text { tsetupf } f l p=Z F_{f l p t}-\sum_{t} \sum_{p} \sum_{l \in L p(p)} \sum_{i \in I l(l)} \cos \text { tsetupi }_{i l p} * Z I_{i l p t} \\
& -\sum_{t} \sum_{a} \sum_{p \in P a(a)} \sum_{i \in I p(p)} \cos t t a_{i p a} * C T A_{i p a t}-\sum_{t} \sum_{a} \sum_{i \in I a(a)} \cos \text { tina }{ }_{i a} * I N A_{i a t} \\
& -\sum_{t} \sum_{i} \sum_{b \in B i(i)} \sum_{a \in A b(b)} \cos t s c_{i b} * C S C_{i b a t}-\sum_{t} \sum_{a} \sum_{q \in Q a(a)} \sum_{i \in I q(q)} \cos t t c l_{i a q} * C T C L_{i a q t} \\
& -\sum_{t} \sum_{q} \sum_{w \in W q(q)} \sum_{i \in I w(w)} \cos t t t k_{i q w} * C T T K_{i q w t}
\end{aligned}
$$

Objective $2\left(z_{2}\right)$

To minimise the backlogged demand over the whole planning horizon, expressed in the product units $\left(\mathrm{m}^{2}\right)$ in both warehouses and shops.

$$
\operatorname{Min} z_{2} \cong \sum_{t} \sum_{a} \sum_{i \in I a(a)} D I F A_{i a t}+\sum_{t} \sum_{w} \sum_{i \in I w(w)} D I F T K_{i w t}
$$

\section{Objective $3\left(z_{3}\right)$}

To minimise idle time, expressed in time units (hours), since production lots may be variable (although they must be above a specified minimum) and preparation times are fixed; thus the model should minimise the resulting idle time in terms of the preparation times employed when launching those lots that better adjust to demand which, on the other hand, will generate less storage costs.

$$
\text { Min } z_{3} \cong \sum_{t} \sum_{p} \sum_{l \in L p(p)}\left(\sum_{f \in F l(l)} \text { ssetupf }_{f l p} * Z F_{f l p t}+\sum_{i \in I l(l)}\left(\text { tsetupi }_{i l p} * Z I_{i l p t}+M P_{i l p t} * t f a b_{i l p}\right)-\text { caf }_{l p t}\right)
$$

For each objective function, the decision maker (DM) has imprecise objectives. Symbol " $\cong$ " is the fuzzified version of " $=$ " and refers to the fuzzification of the aspiration levels. Accordingly, Eqs. (1), (2) and (3) are fuzzy, and it is necessary for the DM to simultaneously optimise these conflicting objectives in the imprecise aspiration levels framework. 


\subsection{Constraints}

In this section, we briefly review the constraints originally proposed by Alemany et al. (2010), which are necessary for our proposal.

Constraint (4) is the inventory balance equation for RMs.

$$
I N C_{c p t}=I N C_{c p t-1}+\sum_{r \in R c(c)} C T P_{c r p t}-\sum_{i \in I c(c)}\left(v_{i c} * \sum_{l \in L p(p)} M P_{i l p t}\right) \quad \forall c, p, t
$$

Constraint (5) establishes safety stocks for RMs.

$$
I N C_{c p t} \geq s s c_{c p} \quad \forall c, p, t
$$

Constraint (6) defines the supply capacity available for RMs suppliers.

$$
\sum_{p} C T P_{c r p t} \leq c a_{c r t} \quad \forall c, r \in R c(c), t
$$

Constraint (7) establishes the capacity available for production lines.

$$
\sum_{f \in F l(l)} t_{\text {setupf }} f_{f p} * Z F_{f l p t}+\sum_{i \in I l(l)}\left(t_{\text {setupi }} i_{i l p} * Z I_{i l p t}+t f a b_{i l p} * M P_{i l p t}\right) \leq c a f_{l p t} \quad \forall p, l \in L p(p), t
$$

Constraint (8) is related to the product families to be produced in each line.

$$
M P F_{f l p t}=\sum_{i \in I f(f)} M P_{i l p t} \quad \forall p, l \in L p(p), f \in F l(l), t
$$

Constraint (9) establishes the minimum lot sizes for FGs production.

$$
M P_{\text {ilpt }} \geq \operatorname{lmi} i_{i l p} * X_{\text {ilpt }} \quad \forall p, l \in \operatorname{Lp}(p), i \in I l(l), t
$$

Constraints (10) and (11) allocate products and product families to each line. Parameters M1 and $\mathrm{M} 2$ are large enough integer numbers.

$$
\begin{array}{ll}
M P_{i l p t} \leq M 1 * X_{i l p t} & \forall p, l \in L p(p), i \in I l(l), t \\
M P F_{f l p t} \leq M 2 * Y_{f l p t} & \forall p, l \in \operatorname{Lp}(p), f \in F l(l), t
\end{array}
$$

Constraints (12) to (15) guarantee the control of the setup of FGs and product families.

$$
\begin{array}{ll}
Z I_{\text {ilpt }} \geq X_{\text {ilpt }}-X_{\text {ilpt }-1} & \forall p, l \in \operatorname{Lp}(p), i \in I l(l), t \\
\sum_{i} Z I_{\text {ilpt }} \geq \sum_{i} X_{\text {ilpt }}-1 & \forall p, l \in L p(p), t \\
Z F_{f l p t} \geq Y_{f l p t}-Y_{f l p t-1} & \forall p, l \in \operatorname{Lp}(p), f \in F l(l), t
\end{array}
$$




$$
\sum_{f} Z F_{f l p t} \geq \sum_{f} Y_{f l p t}-1 \quad \forall p, l \in L p(p), t
$$

Constraint (16) ensures the accomplishment of the family run length

$$
\sum_{t=t^{\prime}}^{t^{\prime}+t m f_{f l p}-1} Z F_{f l p t} \leq 1 \quad \forall p, l \in L p(p), f \in F l(l), t^{\prime}=1, . ., T-t m f_{f l p}+1
$$

Constraint (17) ensures that only first quality FGs are transported to the central warehouses.

$$
\sum_{l \in L p(p)}\left(1-c m_{i}\right) * c q_{i} * M P_{i l p t}=\sum_{a \in A p(p)} C T A_{i p a t} \quad \forall p, i \in \operatorname{Ip}(p), t
$$

Constraints (18) to (21) are related to subcontracting decisions. These constraints also ensure that the amount of subcontracted FGs is transported to the warehouses.

$$
\begin{array}{ll}
\sum_{a \in A b(b)} C S C_{i b a t} \geq \min _{i b} * S_{i b t} & \forall i \in P F S P, b \in B i(i), t \\
\sum_{a \in A b(b)} C S C_{i b a t} \geq \min _{i b} * S_{i b t} & \forall i \in P F S T, b \in B i(i), t \\
\sum_{a \in A b(b)} C S C_{i b a t} \leq \operatorname{casc}_{i b t} * S_{i b t} & \forall i \in P F S P, b \in B i(i), t \\
\sum_{a \in A b(b)} C S C_{i b a t} \leq \operatorname{casc}_{i b t} * S_{i b t} & \forall i \in P F S T, b \in B i(i), t
\end{array}
$$

Constraint (22) establishes safety stocks for FGs.

$$
I N A_{i a t} \geq s s a_{i a} \quad \forall a, i \in \operatorname{Ia}(a), t
$$

Constraint (23) fixes the warehouses capacity.

$$
\sum_{i \in \operatorname{Ia}(a)} I N A_{\text {iat }} \leq \text { capal }_{a} \quad \forall a, t
$$

Constraints (24) and (25) are inventory balance equations for the FGs in warehouses.

$$
\begin{aligned}
& I N A_{i a t}=I N A_{i a t-1}+\sum_{p \in P a(a)} C T A_{i p a t}-V E A_{i a t}-\sum_{q \in Q a(a)} C T C L_{\text {iaqt }} \quad \forall i \in P F N S, a, t \\
& I N A_{i a t}=I N A_{\text {iat }-1}+\sum_{p \in P a(a)} C T A_{\text {ipat }}+\sum_{b \in B a(a) \wedge b \in B(i)} C S C_{i b a t}-V E A_{i a t}-\sum_{q \in Q a(a)} C T C L_{\text {iaqt }} \quad \forall i \in P F S P, a, t
\end{aligned}
$$

Constraint (26) is similar to (24) and (25), but also ensures that subcontracted FGs only come from FG suppliers. 


$$
I N A_{i a t}=I N A_{i a t-1}+\sum_{b \in B a(a) \wedge b \in B i(i)} C S C_{i b a t}-V E A_{\text {iat }}-\sum_{q \in Q a(a)} C T C L_{\text {iaqt }} \quad \forall i \in P F S T, a, t
$$

The backorder quantities in warehouses are calculated using Constraint (27).

$$
V E A_{\text {iat }}+D I F A_{\text {iat }}-D I F A_{\text {iat }-1}=d a_{\text {iat }} \quad \forall a, i \in \operatorname{Ia}(a), t
$$

Constraint (28) limits the backorder quantities in warehouses.

$$
D I F A_{\text {iat }} \leq \alpha 1^{*} d a_{\text {iat }} \quad \forall a, i \in \operatorname{Ia}(a), t
$$

Constraints (29) and (30) are the inflows and outflows of FGs through each logistic centre and shop, respectively.

$$
\begin{array}{ll}
\sum_{a \in A q(q)} C T C L_{\text {iaqt }}=\sum_{w \in W q(q)} C T T K_{\text {iqwt }} & \forall q, i \in I q(q), t \\
C T T K_{i q w t}=V E T K_{i w t} & \forall w, q \in Q w(w), i \in I w(w), t
\end{array}
$$

Constraint (31) determines the backorder quantities in shops.

$$
V_{E T K_{i w t}}+\text { DIFTK }_{i w t}-\text { DIFTK }_{i w t-1}=d t k_{i w t} \quad \forall w, i \in I w(w), t
$$

Constraint (32) limits the backorder quantities in shops.

$$
\operatorname{DIFTK}_{i w t} \leq \alpha 2 * d t k_{i w t} \quad \forall w, i \in \operatorname{Iw}(w), t
$$
(31).

The model also contemplates non-negativity constraints and the definition of binary variables

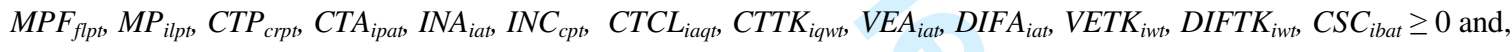

$$
\begin{aligned}
& X_{i l p t}, Y_{f l p t}, Z F_{f l p t}, Z I_{i l p t}, S_{i b t} \in\{0, I\} \\
& \forall f \in F, \forall i \in I, \forall c \in C, \forall l \in L, \forall p \in P, \forall a \in A, \forall q \in Q, \forall w \in W, \forall r \in R, \forall b \in B, \forall t \in T
\end{aligned}
$$

Finally, some decision variables can be defined as integers, but they could change depending on the real-world problem to which the model is applied.

\section{Solution methodology}

In this section, the solution methodology proposed by Peidro et al. (2010) is adopted as the basis of this work. This previous work defines an approach to transform a fuzzy multi-objective linear programming model (FMOLP) into an equivalent auxiliary crisp mathematical programming model for a supply chain transport planning problem in the automobile industry. This approach adopts linear membership functions to represent all the fuzzy objective functions together with the fuzzy programming solution method of Torabi and Hassini (TH) (2008).

According to Torabi and Hassini [3], a multi-objective model could be transformed into a singleobjective model as follows:

$$
\begin{aligned}
& \operatorname{Max} \lambda(x)=\gamma \lambda_{0}+(1-\gamma) \sum_{k} \theta_{k} \mu_{z_{k}}(x) \\
& \text { s.t. } \quad \lambda_{0} \leq \mu_{z_{k}}(x) \quad k=1, \ldots, n
\end{aligned}
$$




$$
\begin{aligned}
& x \in F(x) \\
& \lambda_{0}, \gamma \in[0,1]
\end{aligned}
$$

where $\mu_{z_{k}}$ and $\lambda_{0}=\min \left\{\mu_{z_{k}}(x)\right\}$ denote the degree of satisfaction of the kth objective function and the minimum degree of satisfaction of the objectives, respectively. Moreover, $\theta_{k}$ and $\gamma$ indicate the relative importance of the $k$ th objective function and the compensation coefficient, respectively. The $\theta_{k}$ parameters are determined by the DM based on her/his preferences so that $\sum_{k} \theta_{k}=1, \theta_{k}>0$. The compensation coefficient determines whether the solution obtained will be balanced; in other words, if it gives the same importance to all the objectives; or if it is unbalanced; that is, prioritising those objectives whose $\theta_{k}$. weight is greater. Any parameter $y$ values close to one will provide more balanced solutions; otherwise, values close to zero will generate solutions with better results for those objectives whose weight is greater. It is the DM's task to determine which type of solutions he/she wishes to obtain when applying the present solution methodology.

The interactive solution procedure, adopted from Peidro et al. (2010), is summarised as follows:

- Step 1. Formulate the original FMOLP model according to Eqs. (1) to (33).

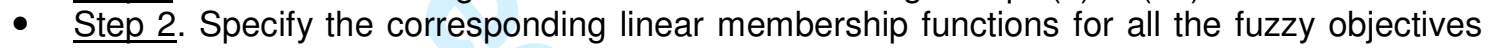
(upper and lower limits).

- Step 3. Determine the corresponding relative importance of the objective functions $\left(\theta_{k}\right)$ and the compensation coefficient $(\gamma)$.

- Step 4. Transform the original FMOLP problem into an equivalent single-objective MILP form using the TH fuzzy programming method.

- Step 5. Solve the proposed auxiliary crisp single-objective model by the MIP solver and obtain the initial solution.

- Step 6. If the DM is satisfied with this current efficient compromise solution, stop. Otherwise, go back to Step 2 and provide another efficient solution by changing the controllable parameters value $\left(\gamma\right.$, and $\left.\theta_{k}\right)$.

\section{Application to a ceramic tile supply chain}

This section uses the example provided by Alemany et al. (2010) to validate and evaluate the results of our proposal. It is an SC that is representative of the ceramic tile sector. There are 3 production plants which produce 4 FGs grouped into 3 product families whose rates, minimum run lengths and fixed costs are provided. Each plant has 2 production lines. All the product families may be manufactured on the production lines in the 3 plants. Six-week periods are considered in the planning horizon. In addition, the following information is provided: bill of materials, transportation costs, setup costs, initial inventory, available production and storage capacities, raw material costs, safety stocks, inventory costs, setup times, production costs, sale prices, subcontracting costs, backorder costs, production run times, minimum lot sizes and demand. Details of this data used can be found in Alemany et al. (2010).

\subsection{Implementation and resolution}

The proposed model has been developed in the MPL language, V4.2. The resolution has been carried out with optimisation solver CPLEX 9. Finally, the input data and the model solution values have been processed with the Microsoft Access database (2007). The experiment was run on a PC with a $2.40 \mathrm{GHz}$ processor and $4 \mathrm{~GB}$ of RAM, and a limited calculation time of 120 seconds was defined. 
In the above-described solution methodology application, the DM provides the relative importance of the objectives as: $\theta_{1}>\theta_{2}>\theta_{3}, \theta=(0.5,0.35,0.15)$. In this case, the total gross margin is more important for the DM over the time periods followed by minimising backlogged demand and, finally, by minimising idle time. Thus, an unbalanced compromise solution with the highest degree of satisfaction for $z 1$ and $z 2$ is of particular interest.

\subsection{Evaluation of the results}

This section compares the results obtained by the mixed integer linear programming model proposed in Alemany et al. (2010) with those obtained by the heuristic procedure and the FMOLP solution methodology proposed in this work.

Table 2. Comparison of the results.

\begin{tabular}{|c|c|c|c|c|c|c|}
\hline Item & Deterministic & $\begin{array}{c}\begin{array}{c}\text { Proposed } \\
\text { method } \\
(\gamma=0.1)\end{array}\end{array}$ & $\begin{array}{c}\begin{array}{c}\text { Proposed } \\
\text { method } \\
(\gamma=0.3)\end{array}\end{array}$ & $\begin{array}{c}\begin{array}{c}\text { Proposed } \\
\text { method } \\
(\gamma=0.5)\end{array}\end{array}$ & $\begin{array}{c}\begin{array}{c}\text { Proposed } \\
\text { method } \\
(\gamma=0.7)\end{array}\end{array}$ & $\begin{array}{c}\begin{array}{c}\text { Proposed } \\
\text { method } \\
(\gamma=0.9)\end{array}\end{array}$ \\
\hline $\begin{array}{l}\text { Objective } \\
\text { values }\end{array}$ & $\begin{array}{c}z_{1}=368,232.4 € \\
z_{2}=0 \\
z_{3}=617.23 \mathrm{~h} .\end{array}$ & $\begin{array}{c}z_{1}=364,246.6 € \\
z_{2}=0 \\
z_{3}=368.78 \mathrm{~h} .\end{array}$ & $\begin{array}{c}z_{1}=349,243.1 € \\
z_{2}=0 \\
z_{3}=185.30 \mathrm{~h} .\end{array}$ & $\begin{array}{c}z_{1}=349,172.9 € \\
z_{2}=0 \\
z_{3}=186.30 \mathrm{~h} .\end{array}$ & $\begin{array}{c}z_{1}=349,117.2 € \\
z_{2}=0 \\
z_{3}=184.96 \mathrm{~h} .\end{array}$ & $\begin{array}{c}z_{1}=349,079.2 € \\
z_{2}=0 \\
z_{3}=185.30 \mathrm{~h} .\end{array}$ \\
\hline $\begin{array}{l}\text { Total } \\
\text { solution } \\
\text { time }\end{array}$ & $40.76 \mathrm{sec}$. & $120 \mathrm{sec}$. & $120 \mathrm{sec}$. & $120 \mathrm{sec}$. & $120 \mathrm{sec}$. & $120 \mathrm{sec}$. \\
\hline$\lambda_{0}$ value & \multirow{8}{*}{ Not applicable } & $\lambda_{0}=0.4052$ & $\lambda_{0}=0.7011$ & $\lambda_{0}=0.6995$ & $\lambda_{0}=0.7016$ & $\lambda_{0}=0.7011$ \\
\hline$\lambda(x)$ value & & $\lambda(x)=0.8233$ & $\lambda(x)=0.7752$ & $\lambda(x)=0.7528$ & $\lambda(x)=0.7330$ & $\lambda(x)=0.7116$ \\
\hline$\mu_{z 1}$ & & 0.9662 & 0.8780 & 0.8775 & 0.8772 & 0.8769 \\
\hline$\mu_{z 1}$ & & 1 & 1 & 1 & 1 & 1 \\
\hline$\mu_{z 3}$ & & 0.4052 & 0.7011 & 0.6995 & 0.7016 & 0.7011 \\
\hline$\left[z_{1}^{l}, z_{1}^{u}\right]$ & & \multicolumn{5}{|c|}{$\begin{array}{l}z_{1}^{l}=200,000 \\
z_{1}^{u}=370,000\end{array}$} \\
\hline$\left[z_{2}^{l}, z_{2}^{u}\right]$ & & \multicolumn{5}{|c|}{$\begin{array}{c}z_{2}^{l}=0 \\
z_{2}^{u}=500\end{array}$} \\
\hline$\left[z_{3}^{l}, z_{3}^{u}\right]$ & & \multicolumn{5}{|c|}{$\begin{array}{c}z_{3}^{l}=0 \\
z_{3}^{u}=620\end{array}$} \\
\hline
\end{tabular}

Table 2 presents the comparisons of the results obtained by the two approaches for all the objectives identified. Furthermore, details are provided of the total solution time employed by each approach, the minimum degree of satisfaction of the objectives $\left(\lambda_{0}\right)$, the equivalent crisp model goal value according to the TH approach $(\lambda(x))$, the degree of satisfaction of the goal functions, as well as the upper and lower limits specified by the DM to define the linear membership functions that are representative of the fuzzy objectives. The $\lambda_{0}, \lambda(x) \mu_{z 1}, \mu_{z 2}, \mu_{z 3}$, values and the upper and lower limits are only significant for the proposed approach, and are not applicable to the deterministic model.

As Table 2 shows, the results obtained by the approach proposed for the case of $\gamma=0.1$ are the most appropriate. As mentioned previously, it is worth remembering that when the DM defines the weights of the objectives, he/ she should have opted for a more unbalanced solution that prioritises those objectives with greater weights. In the case of $y=0.1$, the two proposed approaches offer 
similar results for objectives $z 1$ and $z 2$, and substantial improvement $(40.25 \%)$ in idle time terms. In this particular case, the minimum degree of satisfaction is lower $\left(\lambda_{0}=0.4052\right)$ than for the other compensation coefficient values. This is mainly due to the proposed model prioritising objectives $z 1$ and $z 2$ more than $z 3$ (whose weight is $\theta_{3}=0.15$ ); $z 3$ sets the minimum degree of satisfaction value.

For those compensation coefficient values above $0.1(y>0.1)$, the proposed approach performs in a similar fashion. For these $y$ values, the proposed model tends to obtain more balanced solutions, without paying attention to the weights defined by the DM. This is the reason why the result for objective $z 3$ considerably improves (an improvement of up to $70 \%$ if compared to the deterministic model), and obtains higher minimum degree of satisfaction values. In contrast, the objective $z 1$ values slightly worsen if compared to the deterministic model (by up to $5.2 \%$ ). The $\lambda(x)$ value lowers as the compensation coefficient value increases. According to Eq. (11), this is due to the fact that when $y$ increases, the weight of the minimum degree of satisfaction becomes higher than the result of $\lambda(x)$, and is below the weight of the degrees of satisfactions of all the objectives as a whole.

The approach proposed in this work performs than the single-objective deterministic approach proposed in Alemany et al. (2010). The defined solution methodology offers better results than the deterministic model, similar results in terms of maximising the total gross margin, equal results as regards minimising backlogged demand (which is zero in all cases), and better results when minisiming idle time. When it comes to solving the model, it also offers flexibility for the DM as it enables both unbalanced and balanced solutions. It is the DM who must decide which combination of parameters best satisfies his/her needs.

\section{Conclusions}

This paper continues the work of Alemany et al. (2010) and proposes an FMOLP model to solve the master planning problem for the replenishment-production-distribution of SCs in the ceramic sector for the purpose of maximising the total gross margin, minimising backorder quantities and minimising the idle production time in multi-supplier, multi-plant, multi-type, multi-level distribution centres with a multi-item and multi-period logistic environment. For the purpose of solving the FMOLP model, we followed an interactive solution methodology.

The interactive solution methodology yields an efficient compromise solution and presents the DM's overall satisfaction with the determined goal values in a multi-objective master planning problem for a centralised replenishment, production and distribution ceramic tile supply chain. This approach provides solutions that are consistent with the DM's preferences (i.e., the consistency between weight vector $\theta_{k}$ and the satisfaction vector) because it is able to find different efficient solutions for a specific problem with a given weight vector $\theta_{k}$ by changing the $\gamma$ value. We show that a compromise solution is obtained which, in relation to the previous work (Alemany et al. 2010), improves the utilisation of the production resources by minimising the idle time without considerably lowering the gross margin and/or increasing backorder quantities. Moreover, our fuzzy model solution is robust as regards the fuzziness in the problem without causing an explosive growth of computational effort. At this point, the use of metaheuristics to improve the efficiency of the solution methodology will be a forthcoming work. Finally, this work assumes that the linear membership functions for the related objective functions are reasonably provided. In real-world situations, however, the DM should generate suitable membership functions based on subjective judgement and/or historical resources. Future studies on non-linear membership functions to solve the multiobjective master planning problem in a ceramic tile SC may apply. 


\section{References}

Alemany, M.M.E., Boj, J.J., Mula, J., Lario, F.C., 2010, Mathematical programming model for centralized master planning in ceramic tile supply chains. International Journal of Production Research, In press. DOI: 10.1080/00207540903055701.

Beamon, B.M., 1998, Supply chain design and analysis: Models and methods. International Journal of Production Economics, 55 (3), 281-294.

Chen, C.L., Lee, W.C., 2004, Multi-objective optimization of multi-echelon supply chain networks with uncertain product demand and prices. Computers and Chemical Engineering, 28, 1131-1144.

Chern, C.C., Hsieh, J.S., 2007, A heuristic algorithm for master planning that satisfies multiple objectives. Computers and Operations Research, 34, 3491-3513.

Kreipl, S., Pinedo, M., 2004, Planning and scheduling in supply chains: An overview of issues in practice, Production and Operations Management, 13 (1) 77-92.

Lai, Y., Hwang, C., 1993, Possibilistic linear programming for managing interest rate risk. Fuzzy Sets and Systems, 54, 135-146.

Li, X., Zhang, B., Li, H., 2006, Computing efficient solutions to fuzzy multiple objective linear programming problems. Fuzzy Sets and Systems, 157, 1328-1332.

Mula, J., Peidro, D., Díaz-Madroñero, M., Vicens, E., 2010a, Mathematical programming models for supply chain production and transport planning. European Journal of Operational Research, 204, 377-390.

Mula, J., Peidro, D., Poler, R., 2010b, The effectiveness of a fuzzy mathematical programming approach for supply chain production planning with fuzzy demand. International Journal of Production Economics, In press.

Park, Y.B., 2005, An integrated approach for production and distribution planning in supply chain management, International Journal of Production Research 43 (6) 1205-1224.

Peidro, D., Mula, J., Poler, R., Lario, F.C., 2009a, Quantitative models for supply chain planning under uncertainty: a review. International Journal of Advanced Manufacturing Technology, 43: 400420.

Peidro, D., Mula, J., Poler, R., Verdegay, J.L., 2009b, Fuzzy optimization for supply chain planning under supply, demand and process uncertainties. Fuzzy Sets and Systems, 160, 2640-2657.

Peidro, D., díaz-Madroñero, M., Mula, J., 2010, An interactive fuzzy multi-objective approach for operational transport planning in an automobile supply chain. WSEAS Transactions on Information Science and Applications, 7 (2), 283-294.

Selim, H., Am, C., Ozkarahan, I., 2008, Collaborative production-distribution planning in supply chain: a fuzzy goal programming approach. Transportation Research Part E-Logistics and Transportation Review, 44, 396-419. 
Selim, H., Ozkarahan, I., 2008, A supply chain distribution network design model: An interactive fuzzy goal programming-based solution approach. The International Journal of Advanced Manufacturing Technology, 36, 401-418.

Torabi, S., Hassini, E., 2008, An interactive possibilistic programming approach for multiple objective supply chain master planning. Fuzzy Sets and Systems, 159, 193-214.

von Lanzenauer, Ch., Pilz-Glombik, H.K., 2002, Coordinating supply chain decisions: an optimization model. OR Spectrum 24 (1), 59-78.

Zimmermann, H., 1978, Fuzzy programming and linear programming with several objective functions. Fuzzy Sets and Systems, 1, 45-46. 